\title{
ANALISIS KINERJA SIMPANG BERSINYAL UNTUK MENINGKATKAN KESELAMATAN PADA SIMPANG DEPOK KOTA DEPOK
}

\author{
Sony Widyawan ${ }^{1}$, Rukman' ${ }^{2}$, \\ 1 Program Studi Manajemen Keselamatan Transportasi Jalan, Politeknik \\ Keselamatan Transportasi Jalan. JI Semeru No. 3 Kota Tegal \\ 2 Program Studi Manajemen Keselamatan Transportasi Jalan, Politeknik \\ Keselamatan Transportasi Jalan. Jl Semeru No. 3 Kota Tegal
}

\begin{abstract}
The problemof transportation isone of the problems faced in Depok, especially at intersections. Problems of traffic congestion and conflicts often occur at signalized intersections, especially at the intersection of four signalized Depok Depok City where one of the efforts made to reduce conflicts in Depok intersection is done by setting the intersection. The methods used in the analysis of the performance of the intersection is the use of calculation on IHCM, while the traffic conflict analysis to determine the level of seriousness of traffic conflicts is by using traffic conflict Technique (TCT) is compared to that conflict VisSim 10. Recommendation is done by using a scheme using a 3-phase elections and 3.5 phase and then make a comparison with the third phase (existing) and selected the most appropriate scenario. From the scheme of recommendations that were made by using the software PTV VISSIM 10 obtained the most appropriate scheme that uses three-phase arrangement. The results of the simulation phase 3 was effective at reducing the number of traffic conflicts and service levels are still in good condition
\end{abstract}

Keywords: Simpang, safety, performance, traffic conflicts, cycle times, PTV VISSIM 10

\begin{abstract}
Abstrak
Masalah transportasi merupakan salah satu masalah yang dihadapi di Kota Depok terutama pada persimpangan. Permasalahan kemacetan dan konflik lalu lintas sering terjadi pada simpang bersinyal terutama pada simpang empat bersinyal Depok Kota Depok yang mana salah satu upaya yang dilakukan untuk mengurangi konflik pada simpang Depok adalah dengan melakukan pengaturan pada simpang.. Metode yang digunakan dalam analisis kinerja simpang adalah menggunakan perhitungan pada MKJI, sedangkan analisis konflik lalu lintas untuk mengetahui tingkat keseriusan konflik lalu lintas adalah dengan menggunakan metode Traffic Conflict Technique (TCT) yang dibandingkan dengan konflik pada Vissim 10. Rekomendai yang dilakukan adalah dengan menggunakan pemilihan skema menggunakan 3 fase dan 3,5 fase yang selanjutnya dilakukan perbandingan dengan 3 fase (eksisting) dan dipilih skenario yang paling tepat. Dari skema rekomendasi yang telah dilakukan dengan menggunakan software PTV Vissim 10 didapatkan skema yang paling tepat yaitu menggunakan pengaturan 3 fase. Hasil dari simulasi 3 fase ternyata efektif mengurangi jumlah terjadinya konflik lalu lintas dan tingkat pelayanan masih dalam kondisi baik.
\end{abstract}

Kata Kunci:Simpang, keselamatan, kinerja, konflik lalu lintas, waktu siklus, PTV Vissim 10 


\section{PENDAHULUAN}

Kota Depok merupakan salah satu kota penunjang kegiatan di DKI Jakarta dan Kabupaten Bogor dengan kondisi transportasi yang cukup ramai. Peningkatan produksi pada Kota Depok dapat mempercepat laju pertumbuhan ekonomi yang akan berdampak dalam peningkatan mobilitas. Dengan melihat perkembangan pada kota serta pertumbuhan penggunaan kendaraan bermotor yang semakinmeningkat sehingga menimbulkan masalah baru khususnya di sektor transportasi.

Selain permasalahan penyediaan prasarana jalan yang tidak sebanding dengan pertambahan jumlah kendaraan, juga permasalahan seperti hambatan pada ruas dan simpang, sehingga menimbulkan kemacetan. Permasalahan transportasi berupa kemacetan, tundaan atau hambatan, kecelakaan lalu lintas, naik turun penumpang dan parkir angkutan umum dan penyeberang pejalan kaki yang mempengaruhi kinerja simpang.

Permasalahan pada simpang memiliki penyebab yang dapat mempengaruhi kinerja simpang. Persimpangan merupakan simpul pada jaringan jalan dimana ruas-ruas jalan bertemu dan lintasan kendaraan berpotongan yang menyebabkan volume lalu lintas tinggi. Selain itu desain geometri dan jarak pandang simpang yang buruk, kurangnya pengaturan angkutan umum, penyeberang pejalan kaki, dan pengendalian persimpangan yang kurang tepat.

Persimpangan merupakan faktor penting pada sistem jaringan jalan. Pengendalian pada setiap persimpangan selalu menjadi faktor penting didalam menentukan kinerja (performance) dan kapasitas keseluruhan jaringan jalan. Untuk itu masalah pengendalian arus lalu lintas di persimpangan menjadi sangat vital guna meningkatkan kinerja dan keselamatan simpang.

Simpang Depok merupakan pertemuan antara Jalan Raya Bogor dengan Jalan Tole Iskandar. Jalan Raya Bogor merupakan jalan arteri primer dengan volume lalu lintas yang tinggi dan Jalan Tole Iskandar merupakan jalan kolektor primer yang memiliki volume yang cukup ramai. Pertemuan antara kedua jalan tersebut menimbulkan kepadatan di Simpang Depok yang berdampak pada tundaan dan kemacetan kendaraan.

Pada pendekat Simpang Depok terdapat pertokoan dan angkutan umum yang berhenti di bahu jalan yang menyebabkan tundaan kendaraan akibat angkutan umum tersebut. Aktifitas pejalan kaki baik menyusuri di tepi jalan ataupun menyeberang di sekitar simpang cukup tinggi meskipun belum adanya fasilitas perlengkapan jalan yang tersedia di Simpang Depok tersebut.

Melihat kondisi transportasi yang terjadi di Kota Depok saat ini khususnya pada simpang Depok, maka perlu dilakukan penelitian mengenai permasalahan transportasi dengan melakukan analisis kinerja simpangbersinyal untuk meningkatkan keselamatan pada simpang Depok. Maka dari itu daerah persimpangan perlu diupayakan memiliki pengaturan fase atau pengendalian yang baik. 


\section{LANDASAN TEORI}

\section{Analisis Kinerja}

Menurut Spradley dalam Sugiyono (2015:335) mengatakan bahwa analisis adalah sebuah kegiatan untuk mencari suatu pola selain itu analisis merupakan cara berpikir yang berkaitan dengan pengujian secara sistematis terhadap sesuatu untuk menentukan bagian, hubungan antar bagian dan hubungannya dengan keseluruhan. Analisis adalah suatu usaha untuk mengurai suatu masalah atau fokus kajian menjadi bagian-bagian (decomposition) sehingga susunan / tatanan bentuk sesuatu yang diurai itu tampak dengan jelas dan karenanya bisa secara lebih terang ditangkap maknanya atau lebih jernih dimengerti duduk perkaranya (Satori dan Komariyah, 2014:200). Secara umum analisis adalah kegiatan merangkum sejumlah data besar yang masih mentah kemudian mengelompokan atau memisahkan komponen-komponen serta bagian-bagian yang relevan untuk kemudian mengkaitkan data yang dihimpun untuk menjawab permasalah.

\section{Arus Lalu Lintas}

Jumlah kendaraan bermotor yang melewati suatu titik pada jalan per satuan waktu, dinyatakan dalam kend/jam (Qkend), smp/jam (Qsmp) atau LHRT ( Lalulintas Harian Rata-Rata Tahunan) (MKJI, 1997). Arus lalu lintas, Q, dinyatakan dalam skr per jam untuk satu atau lebih periode, misalnya pada periode jam puncak pagi, siang, atau sore. Q dikonversi dari satuan kendaraan per jam menjadi skr per jam dengan menggunakan nilai ekivalen kendaraan ringan (ekr) untuk masing-masing pendekat terlindung dan terlawan.

\section{Lampu Lalu Lintas}

Lampu lalu lintas adalah peralatan yang dioperasikan secara mekanis, atau electrik untuk memerintahkan kendaraan-kendaraan agar berhenti atau berjalan. Peralatan standar ini terdiri dari sebuah tiang, dan kepala lampu dengan tiga lampu yang warnanya beda (merah, kuning, hijau).

\section{Konflik Lalu Lintas}

Konflik adalah arus lalu lintas dari berbagai arah akan bertemu pada suatu titik persimpangan,kondisi tersebut menyebabkan terjadinya konflik antara pengguna jalan dari arah yang berbeda (Hobbs, 1995 dalam Setiawan, A.T., 2015). Menurut awalata, Greece Maria (2010).

\section{Keselamatan}

Keselamatan adalah terhindarnya dari bencana, aman sentosa, sejahtera, tidak kurang suatu apapun, sehat, tidak mendapat gangguan, kerusakan, beruntung, tercapai maksudnya, tidak gagal (Poerwadarminta 1976). Arti selamat dapat juga berarti suatu keadaan yang aman serta terhindar dan terlindungi secara fisik, sosial, pekerjaan atau berbagai konsekuensi lain dari kegagalan, kerusakan, kesalahan, kecelakaan, kerugian atau berbagai kejadian lain yang diinginkan. Keselamatan jalan raya merupakan suatu bagian yang tak 
terpisahkan dari konsep transportasi berkelanjutan yang menekankan pada prinsip transportasi aman, nyaman, cepat, bersih (mengurangi polusi / pencemaran udara) dan dapat diakses oleh semua orang dan semua kalangan, baik oleh para penyandang cacat, anak - anak, ibu - ibu, maupun para lanjut usia (Soejachmoen, 2004).

\section{Program Komputer PTV Vissim}

Menurut PTV-AG (2011), VISSIM adalah perangkat lunak multimoda simulasi lalu lintas aliran mikroskopis. VISSIM dikembangkan oleh PTV (Planung Transportasi Verkehr AG) di Karlsruhe, Jerman. VISSIM berasal dari Jerman yang mempunyai nama "Verkehr Städten - SIMulationsmodell" yang beartian model simulasi lalulintas perkotaan. VISSIM diluncurkan pada tahun 1992 dan berkembang sangat baik hingga saat ini.

\section{METODE PENELITIAN}

Penelitian ini dilakukan di simpang Depok Kota Depok dengan memiliki 4 kaki simpang dengan 2 kaki simpang jalan nasional dan 2 kaki simpang yang lain merupakan jalan kota. Berikut adalah bagan alir penelitian ditunjukan pada gambar 1 dibawah ini:

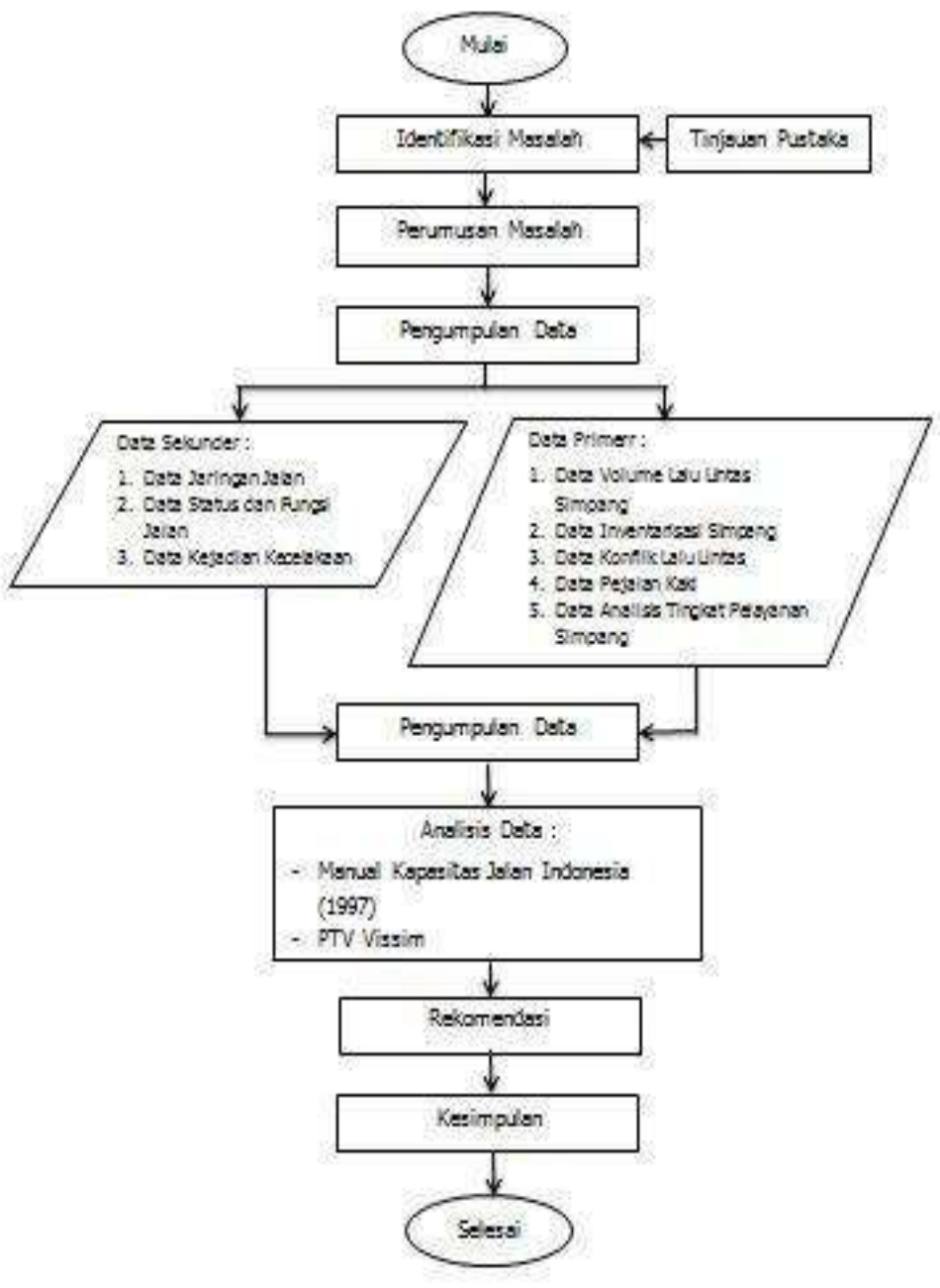

Gambar 1. Bagan Alir Penelitian 


\section{Teknik Pengumpulan Data}

a. Inventarisasi Jalan

Inventrasi tingkat pelayanan yaitu kegiatan pengumpulan data untuk mengetahui tingkat pelayanan pada setiap ruas jalan dan/atau persimpangan meliputi data dimensi dan geometrik jalan, data perlengkapan jalan meliputi jumlah, jenis dan kondisi perlengkapan jalan terpasang.

b. Gerakan Membelok Kendaraan Terklasifikasi / classified turningmovement counting (CTMC)

Data volume lalu lintas digunakan untuk memperoleh data yang akurat mengenai jumlah pergerakan kendaraan disertai dengan jenis kendaraannya yang melintasi suatu persimpangan serta untuk mengetahui jam sibuk / puncak (peak hour).

c. Tingkat Pelayanan Simpang.

Setelah dilakukan survei tingkat pelayanan simpang dengan kondisi eksisting sehingga diperoleh data -data terkait dengan tingkat pelayanan simpang. Maka selanjutnya data tersebut akan dimasukkan dalam rumus sehingga didapatkan tingkat pelayanan Simpang Depok Kota Depok agar dapat memberikan solusi penanganan yang tepat.

d. Konflik Lalu Lintas

Survei konflik dilakukan untuk menghasilkan data yang reliabel. Uji reliabilitas konflik dilakukan untuk memastikan bahwa data yang didapat adalah dapat dipercaya. Untuk melakukan uji reliabilitas menggunakan tabel chi square. Setelah data reliabel, lalu menggunakan tabel time to accident untuk mengklasifikasikonflik yang terjadi termasuk konflik serius atau konflik tidak serius.

Lalu nilai time to accident dari konflik yang terjadi dengan membandingkan antara jarak dan kecepatan maka dilakukan perbandingan antara time toaccident untuk mengklasifikasi tingkatkeseriusan konflik.

Setelah diketahui tingkat keseriusan konflik yang terjadi maka menghitung angka keseriusan konflik per 1000 kendaraan. Hal ini dilakukan untuk menganalisis ada berapa kendaraan yang terlibat konflik dalam setiap 1000 kendaraan (dalam satuan skr).

e. Pejalan Kaki

Sesuai Undang - undang Nomor 22 Tahun 2009 tentang Lalu Lintas dan Angkutan Jalan, Pejalan kaki adalah setiap orang yang berjalan di ruang lalu lintas. Karena aktivitasnya bergerak, maka pejalan kaki dianggap bagian dari pergerakan lalu lintas. Untuk menjamin keselamatan pejalan kaki, maka diatur hak dan kewajibannya dalam berlalu lintas.

\section{Teknik Analisis Data}

Tingkat Pelayanan Simpang

a. Kapasitas (C)

Kapasitas adalah arus lalu lintas maksimum yang masuk ke simpang yang dapat dipertahankan selama waktu paling sedikit satu jam dalam kondisi cuaca dan geometrik yang ada pada saat itu dalam satuan smp/jam (MKJI, 1997).

$\mathbf{C}=\mathbf{S} \cdot \mathbf{g} / \mathbf{C}$ 
Dimana :

C $\quad$ Kapasitas (smp/jam hijau)

$\mathrm{S} \quad=$ Arus jenuh (smp/jam hijau)

g = Waktu hijau (detik)

$\mathrm{c} \quad=$ Panjang siklus (detik)

b. Derajat Kejenuhan (DS)

Derajat kejenuhan diartikan sebagai rasio arus lalu lintas terhadap kapasitas untuk suatu pendekat. Derajat kejenuhan dihitung menggunakan persamaan :

$D S=Q_{C}$

DS = Derajat kejenuhan

$\mathrm{Q}=$ Arus lalu lintas (smp/jam) C = Kapasitas (smp/jam)

C. Tundaan

Menurut MKJI (1997), tundaan adalah waktu tempuh tambahan yang diperlukan kendaraan untuk melalui simpang apabila dibandingkan lintasan tanpa melalui suatu simpang. Tundaan dapat diperoleh melalui perhitungan : $D T_{j}=c \cdot \frac{0,5 \cdot\left(1-G R_{j}\right)}{\left(1-G R_{j} \cdot D S_{j}\right)} \cdot \frac{N Q_{1} \cdot 3600}{C_{j}}$

Dimana :

C = Kapasitas (smp/jam)

C = Waktu siklus (detik)

DS = Derajat kejenuhan.

$\mathrm{GR}=$ Rasio hijau ( $\mathrm{g} / \mathrm{c}$ ) detik)

$\mathrm{NQ}=$ Jumlah smp yang tersisa dari fase hijau sebelumnya

\section{Konflik Lalu Lintas}

Menggunakan metode STCT (SwedishTraffic Conflict Tehnnique) yaitu suatumetode observasi secara langsung untuk mendapatkan data konflik lalu lintas yang terjadi akibat maneuver dari keluar masuknya kendaraan sata parkir dan konflik antara pengguna jalan dengan pejalan kaki baik yg menyusuri maupun yang menyebrang. Time to Accident

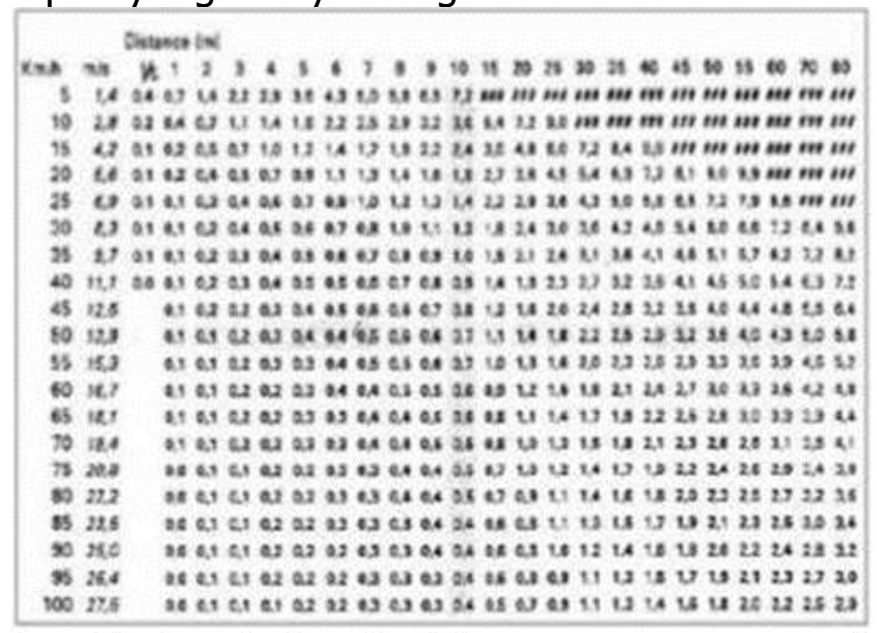

Gambar 2. Time To Accident 
Setelah menegathui nilai Timeto Accident (TA) dengan membandingkan antara jarak dengan kecepatan, dan untuk mengetahui keseriusan konflik yang terjadi maka perlu dilakukan pembandingan antara Tme to Accident (TA) dengankecepatan. Kemudian akan didapatkan bagaimana keseriusann konflik yang terjadi pada simpang yang teliti.

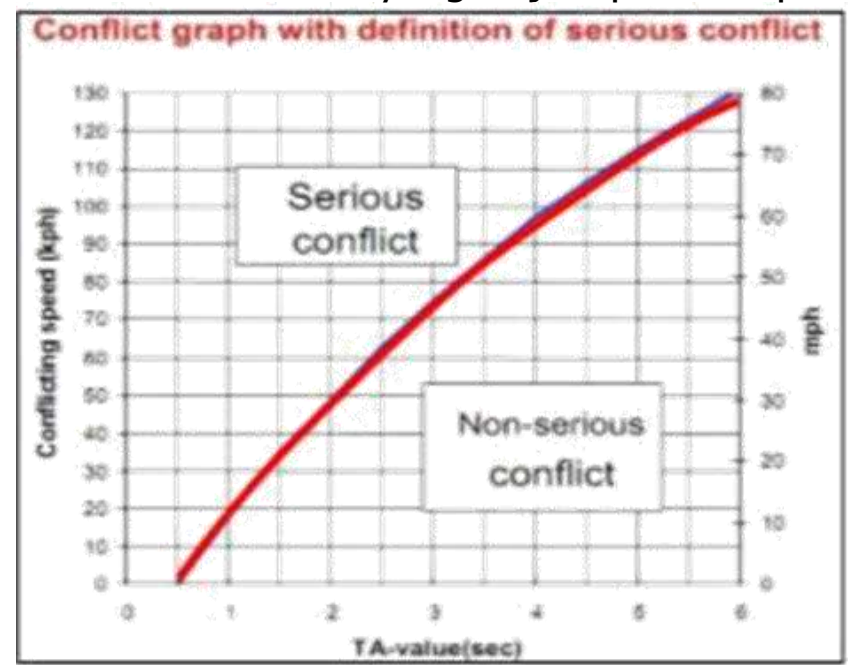

Gambar 3. Grafik Keseriusan Konflik

\section{PEMBAHASAN}

a. Kondisi Eksisting Inventarisasi Jalan

Simpang Depok terletak di Kota Depok yang mempunyai empat kaki simpang yaitu:

Kaki Simpang Utara : Jalan Raya Bogor

Kaki Simpang Selatan : Jalan Raya Bogor

Kaki Simpang Barat : Jalan Tole Iskandar

Kaki Simpang Timur : Jalan Jatijajar 
Tabel 1. Geometri Simpang

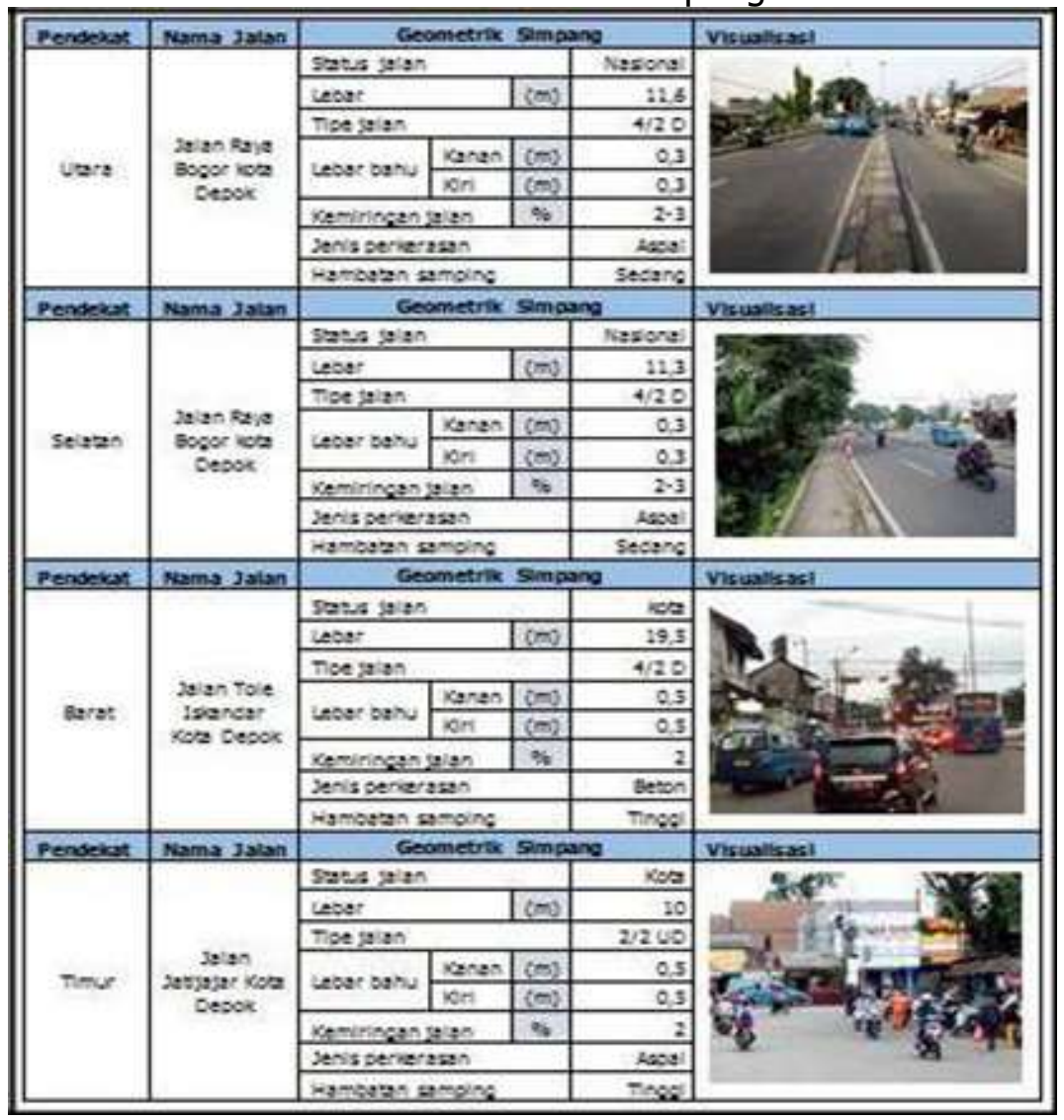

Kinerja Simpang (Eksisting)

Penghitungan fase pada simpang ini yaitu menggunakan tiga fase dan 1 warning light dimana waktu siklustotal adalah 140 detik. Berikut adalah diagram fase simpang Depok dapat dilihat pada gambar berikut :

\begin{tabular}{|c|c|c|c|c|c|c|c|c|c|}
\hline Fase & 55 & 3 & 2 & 25 & 3 & 2 & 45 & 3 & 2 \\
\hline Utara & & & & & & & & & \\
\hline & & & & & & & & & \\
\hline Barat & & & & & & & & \\
\hline & & & & & & & & & \\
\hline Selatan & & & & & & & & \\
\hline & & & & & & & & & \\
\hline Timur & & & & & & & & \\
\hline
\end{tabular}

Gambar 4. Diagram Fase Simpang Depok

Tabel 2. Kinerja Tiap Kaki Simpang Depok dengan 3 fase (Eksisting)

\begin{tabular}{|c|c|c|c|c|c|c|c|}
\hline $\begin{array}{l}\text { Kesl } \\
\text { glomero }\end{array}$ & $\begin{array}{c}\text { Kansits } \\
(C)\end{array}$ & $\begin{array}{l}\text { Wokby } \\
\text { elkis }\end{array}$ & 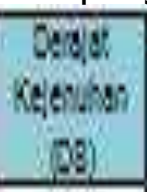 & $\begin{array}{l}\text { Pererg } \\
\text { Anter } \\
\text { NOS }\end{array}$ & $\begin{array}{c}\text { Kenderen } \\
\text { Teng-k } \\
\text { (NB) }\end{array}$ & $\begin{array}{c}\text { Thosen } \\
\text { (O) }\end{array}$ & $\begin{array}{l}\text { Togke: } \\
\text { pegeren } \\
\text { (.09) }\end{array}$ \\
\hline Wes & 144805 & 140. & $0 \% 8$ & 71,18 & 1,19 & 8724 & $F$ \\
\hline seaten & $1176 \%$ & 140 & $0 \%$ & $60 \% 9$ & 18 & $8 \%$ & F \\
\hline 82 & $\$ 1,75$ & 140 & $0 \%$ & 5105 & 1,25 & $115 \% 5$ & F \\
\hline$\pi *$ & $\$ 51,15$ & 140 & $O 9$ & 5105 & 1,25 & 11945 & F \\
\hline
\end{tabular}


Konflik Lalu Lintas

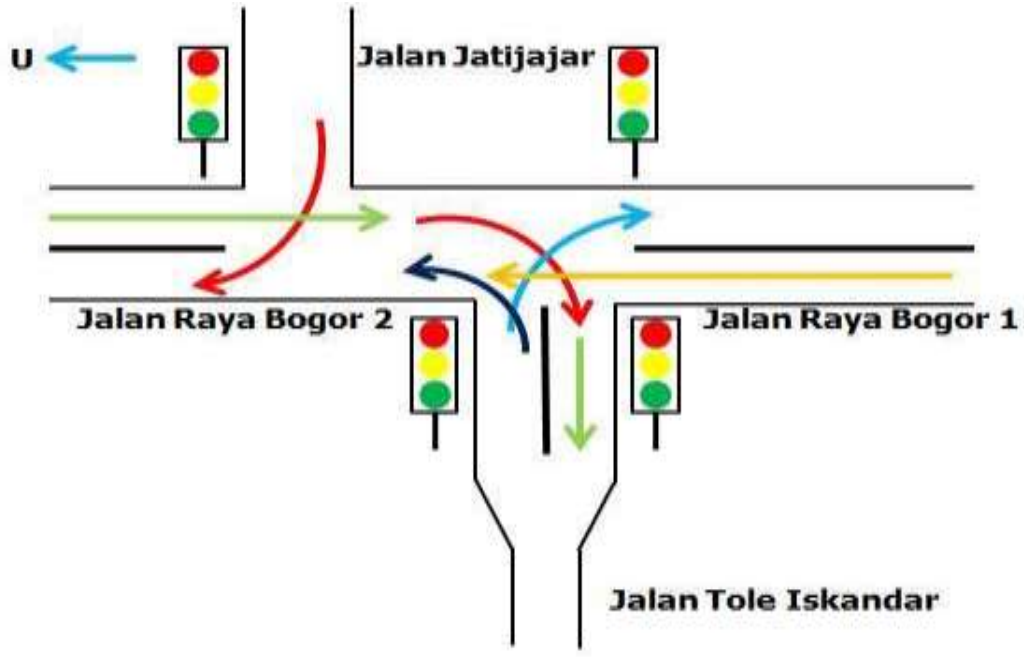

Gambar 5. Ilustrasi PergerakanKonflik Lalu Lintas

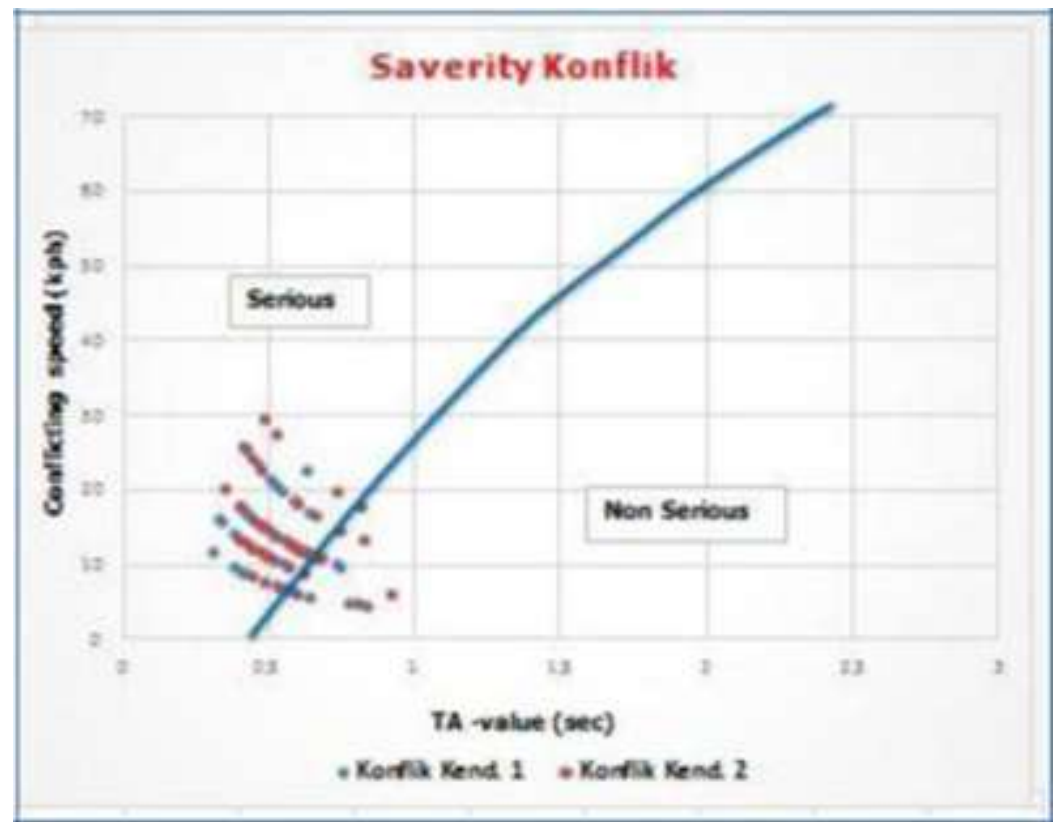

Gambar 6. Tingkat Keseriusan Konflik

Dari Gambar 6 telah menggambarkan terdapat 127 kendaraan bermotor yang terlibat konflik lalu lintas pada simpang Depok dan telah terjadi 63 titik konflik, dengan 81 kendaraan bermotor terlibat konflik serius dan sebanyak 46 kendaraan terlibat konflik non serius. Sedangkan untuk jenis konflik sendiri akan digambarkan pada diagram yang ada pada gambar 7 berikut. 


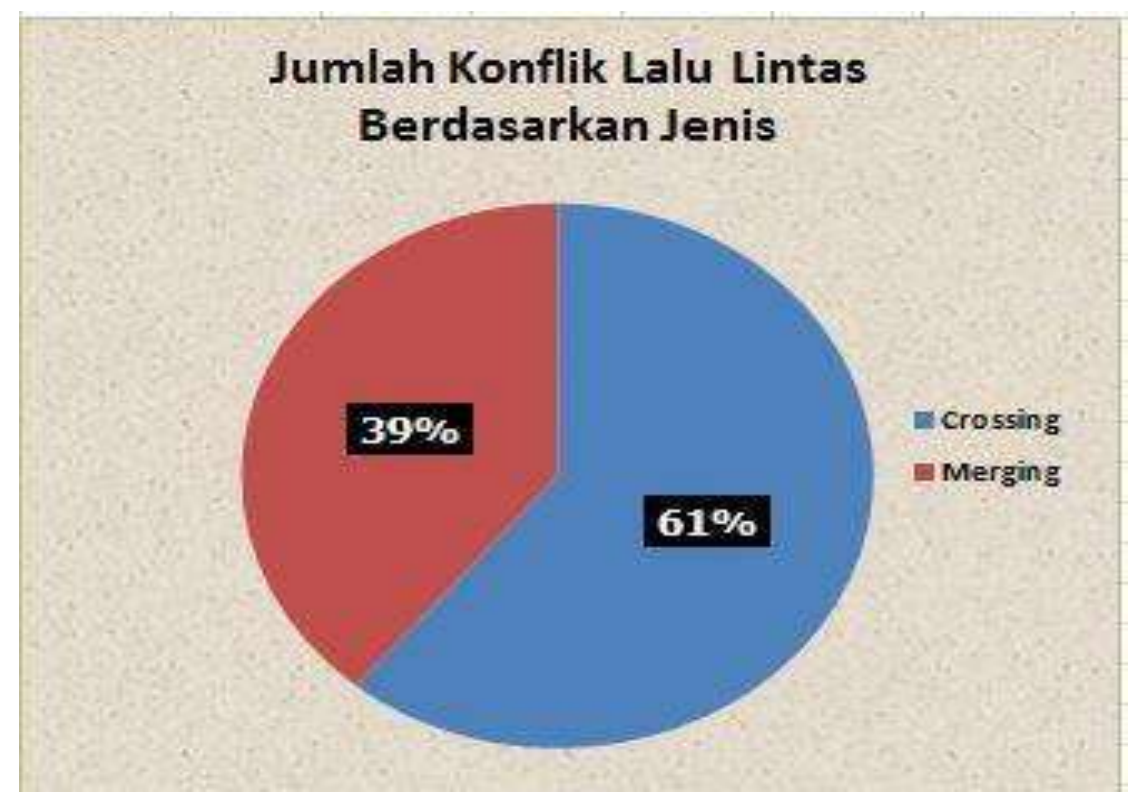

Gambar 7. Prosentase Jenis Konflik

Pada gambar grafik 7 diatas menggambarkan jenis konflik lalu lintas yang terjadi pada waktu peak di simpang Depok yaitu $61 \%$ adalah didominan oleh konflik crossing dan 39\% sisanya adalah konflik merging.

b. Rekomendasi Usulan Penanganan Kinerja Simpang (Rekomendasi 3 fase dan 3,5 fase)

Tabel 3. Kinerja Tiap Kaki Simpang Depok dengan 3 fase (Rekomendasi)

\begin{tabular}{|c|c|c|c|c|c|c|c|}
\hline $\begin{array}{c}\text { Ked } \\
\text { slencero }\end{array}$ & $\begin{array}{c}\text { Kessizs } \\
(0)\end{array}$ & $\begin{array}{l}\text { Wests } \\
\text { akces }\end{array}$ & $\begin{array}{c}\text { Decas } \\
\text { Ke,enver } \\
\text { (0) }\end{array}$ & $\begin{array}{l}\text { Pover } \\
\text { Aoten } \\
\text { Na }\end{array}$ & $\begin{array}{c}\text { Kerces: } \\
\text { teteet } \\
\text { N3) }\end{array}$ & $\begin{array}{c}\text { Trosen } \\
\text { (0) }\end{array}$ & 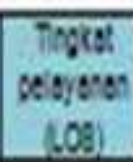 \\
\hline Uas & 14388 & S11 & 0,88 & 8050 & 105 & 9955 & F \\
\hline Sets: & 122195 & 211 & 0,97 & 79,25 & 1,04 & 98,79 & $f$ \\
\hline Eov: & 109565 & : 11 & 0.91 & 6507 & 106 & 11238 & $f$ \\
\hline ingt & 100565 & S11 & 0.91 & 6507 & 108 & 11238 & F \\
\hline
\end{tabular}


Tabel 4. Kinerja Tiap Kaki SimpangDepok dengan 3,5 fase (Rekomendasi)

\begin{tabular}{|c|c|c|c|c|c|c|c|}
\hline $\begin{array}{c}\text { Keri } \\
\text { gimoers }\end{array}$ & $\begin{array}{c}\text { Konsits } \\
(0)\end{array}$ & $\begin{array}{l}\text { Weks } \\
\text { 8kis }\end{array}$ & 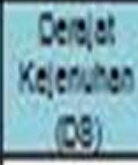 & $\begin{array}{l}\text { Pereres } \\
\text { Nowen } \\
\text { Na }\end{array}$ & $\begin{array}{c}\text { Kerceosen } \\
\text { Tetert } \\
\text { (N) }\end{array}$ & $\begin{array}{l}\text { Toroen } \\
\text { (0) }\end{array}$ & $\begin{array}{l}\text { Tonker } \\
\text { ceseres } \\
(003)\end{array}$ \\
\hline WaO & 1690,15 & 200 & 0,86 & 113,03 & 1,02 & 104,39 & F \\
\hline setern & 2000,86 & 250 & 0,97 & 9406 & 1,04 & 122,40 & f \\
\hline sev: & 11003,60 & 250 & 0,89 & 79,33 & 109 & 127,86 & F \\
\hline Teres & 623,75 & 250 & 1,01 & $\$ 8,4$ & 1,18 & 1839,9 & \& \\
\hline
\end{tabular}

c. Konflik Lalu Lintas (Rekomendasi3 fase dan 3,5 fase)

\section{Jumlah Konflik Lalu Lintas}

Berdasarkan Jenis

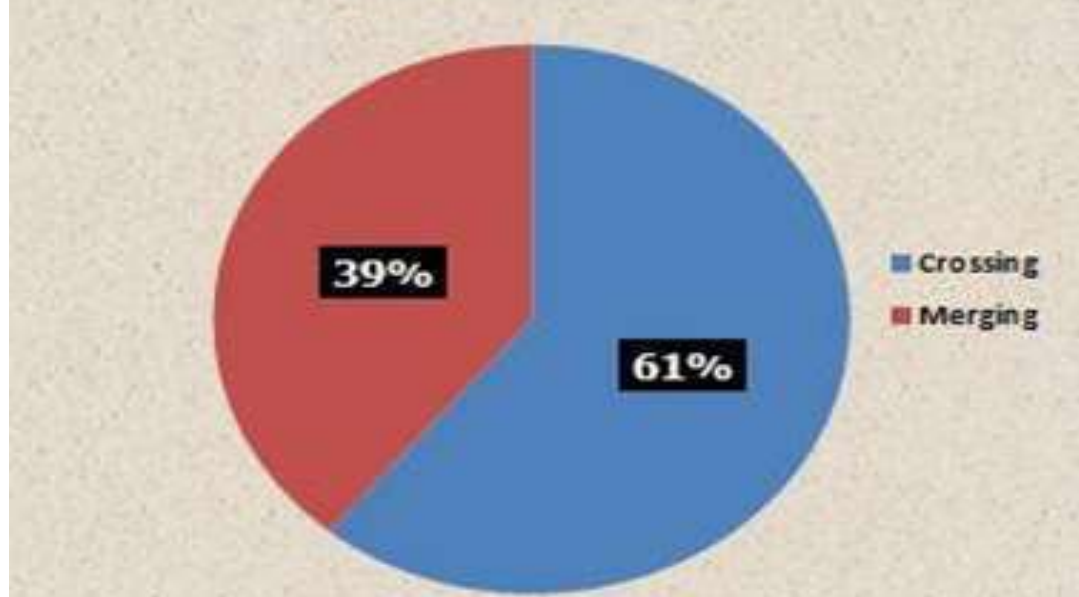

Usulan atau rekomendasi penanganan konflik lalu lintas pada simpang Depok yaitu dengan mengatur ulang fase dan waktu siklus yang tadinya 3 fase dan 1 warning light (eksisting) menjadi 3 fase(rekomendasi) dan 3,5 fase (rekomendasi) yang dilakukan uji coba dengan metode simulasi dengan menggunakan software PTV Vissim for Student. Dari hasil simulasi ini diketahui pergerakan kendaraan yang terjadi di simpang Depok tersebut berikut dengan pengaturan 3fase dan 3,5 fase. Setelah mengamati pergerakan simulasi kendaraan tersebut dapat diketahui arus lalu lintas dan konflik yang terjadi pada simpang tersebut. 


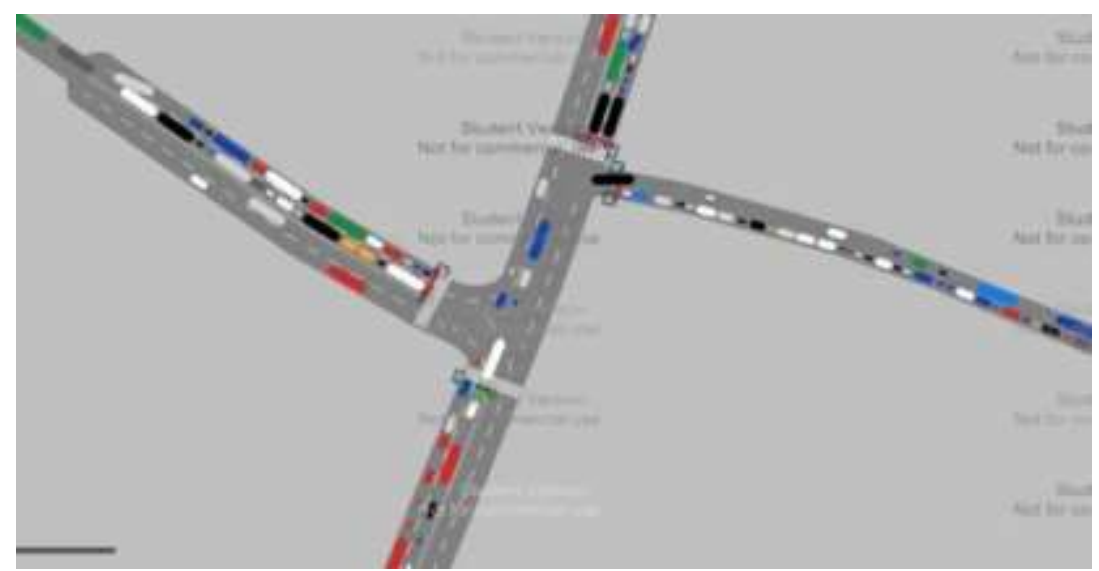

Gambar 8. Simulasi Pengaturan Fase 3 (After)

Dari hasil simulasi tersebut diketahui jumlah konflik lalu lintas yang masih terjadi pada simpang Depok tersebut. Terdapat perbandingan jumlah konflik yang terjadi antara pengaturan 3 fase (eksisting) dengan 3 fase (rekomendasi). Berikut jumlah konflik yang terjadi pada pengaturan simpang menggunakan 3 fase (rekomendasi).

Berikut prosentase dari jumlah konflik 3 fase dapat dilihat pada gambar 9.

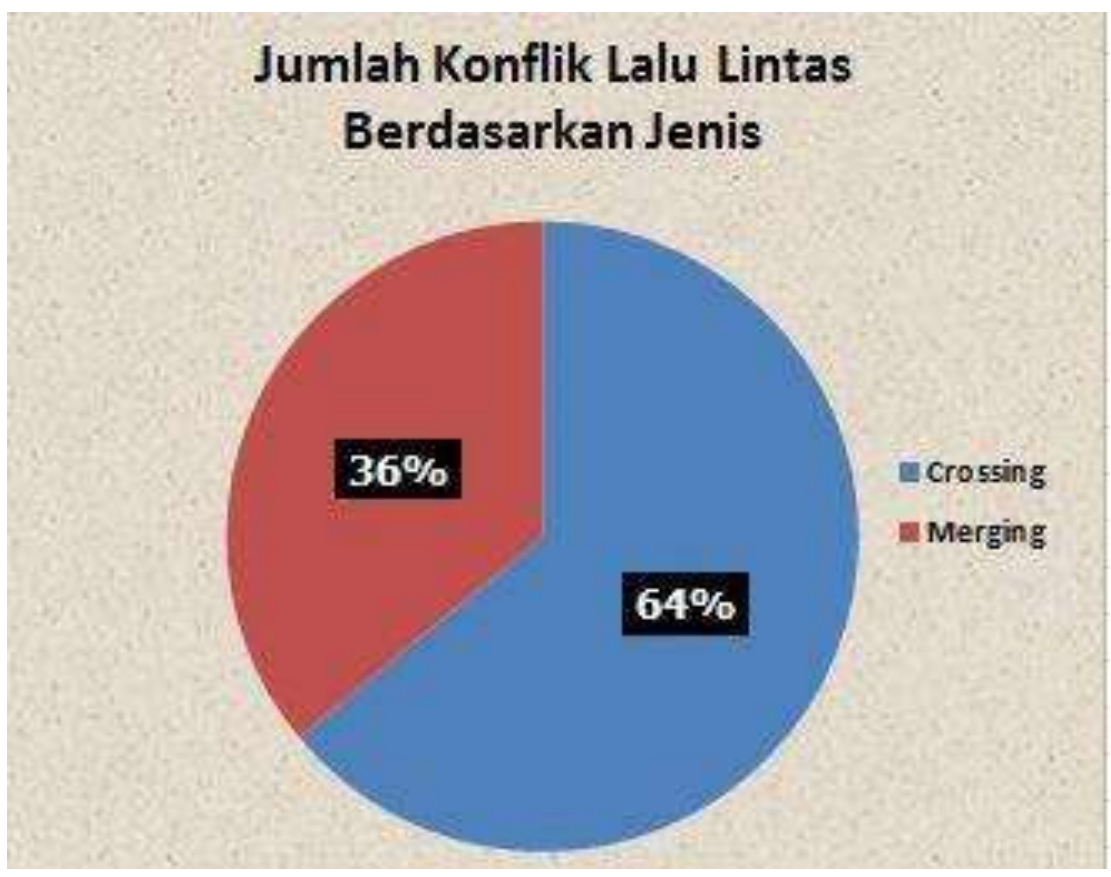

Gambar 9. Jumlah Konflik Lalu Lintas3 Fase (After)

Gambar 9. menggambarkan jumlah kendaraan bermotor yang terlibat konflik lalu lintas yang sebesar $64 \%$ atau sebanyak 58 jumlah konflik crossing dan $36 \%$ atau 32 jumlahkonflik merging. Dari hasil grafik tersebut diketahui jumlah perbandingan konflik dari eksisting (3 fase dan 1 warning light) menjadi rekomendasi (3 fase) yaitu berkurang. 


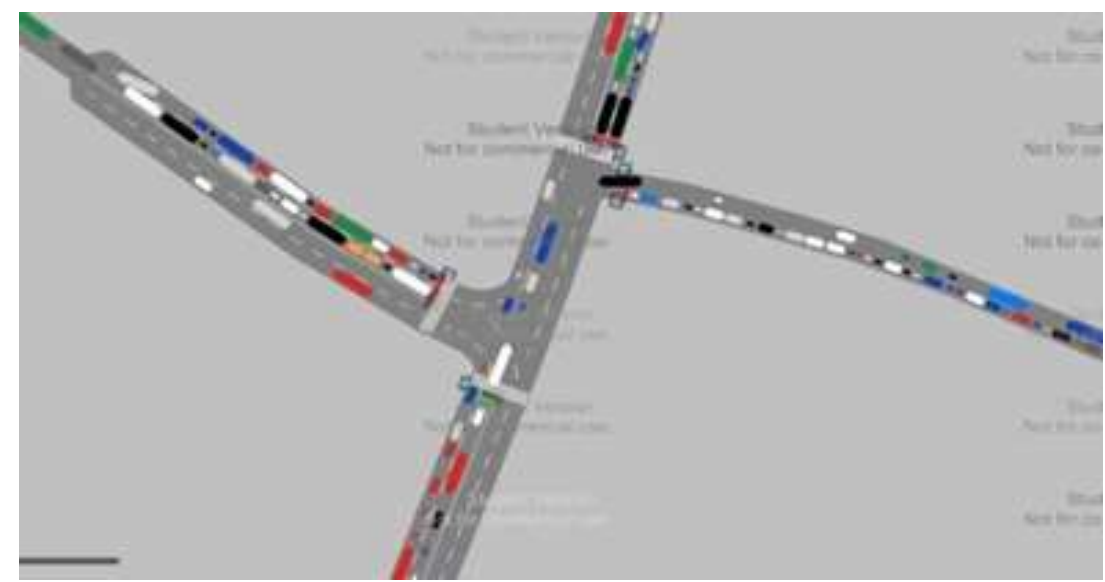

Gambar 10. Simulasi Pengaturan Fase3,5 (After)

Dari hasil simulasi tersebut diketahui jumlah konflik lalu lintas yang masih terjadi pada simpang Depok tersebut. Terdapat perbandingan jumlah konflik yang terjadi antara pengaturan 3 fase (eksisting) dengan 3,5 fase (rekomendasi). Berikut jumlah konflik yang terjadi pada pengaturan simpang menggunakan 3,5 fase.

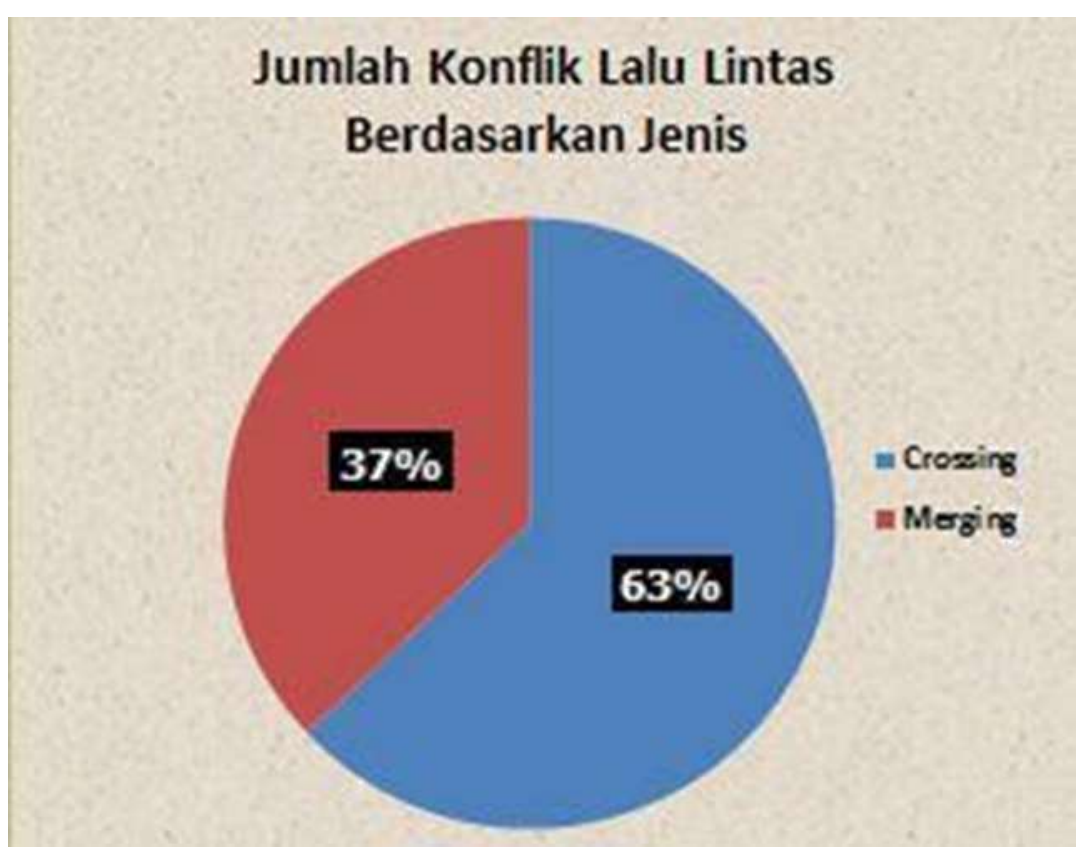

Gambar 11. Jumlah Konflik LaluLintas 3,5 Fase (After)

Gambar 11. menggambarkan jumlah kendaraan bermotor yang terlibat konflik lalu lintas yang sebesar $63 \%$ atau sebanyak 66 jumlah konflik crossing dan 37 $\%$ atau 39 jumlahkonflik merging. Dari hasil grafik tersebut diketahui jumlah perbandingan konflik dari eksisting ( 3 fase dan 1 warning light) menjadi rekomendasi ( 3,5 fase) yaitu berkurang. 
d. Perbandingan Eksisting dan Rekomendasi

Tabel 5. Hasil Perbandingan Fase 3(eksisting) dengan Fase (rekomendasi)

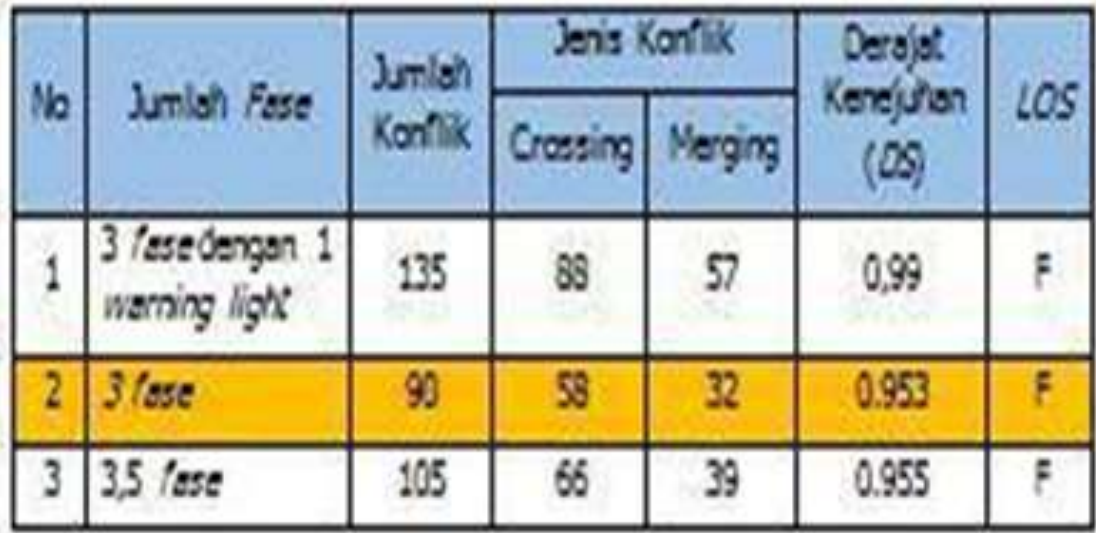

Hasil analisis pada simpang Depok, tingkat pelayanan simpang Depok yaitu pada tingkat pelayanan $\mathrm{F}$ yang mana perlu dilakukan penanganan dan simpang dalam kondisi kritis. Pernyataan ini hasil dari perhitungan tingkat pelayanan simpang bersinyal ketika rekomendasi 3 fase memiliki derajat kejenuhan simpang yaitu 0,953 (F) dibandingkan dengan kondisi eksisting yaitu 3 fase dengan 1 kaki simpang pada Jalan Jatijajar menggunakan warning light memiliki derajat kejenuhan simpang yaitu 0,99 ( F) Rekomendasi menggunaan perubahan menjadi 3 fase yaitu dengan mengaktifkan pengaturan lalu lintas pada Jalan Jatijajar yang sama fasenya sama dengan Jalan Tole Iskandar dapat menurunkan jumlah terjadinya konflik , dimana pada kondisi eksisting terjadi 135 konflik dengan 88 konflik crossing dan 32 konflik merging dan setelah dilakukan perubahan menjadi 3 fase tanpa warning light pada Jalan Jatijajar jumlah konflik menurun menjadi 90 konflik dengan 58 konflik crossing dan 32 konflik merging.Diperlukan perbaikan pada simpang Depok karena simpang tersebut tergolong simpang yang memiliki tundaan yang besar yang akan berimbas pada kemacetan.

\section{KESIMPULAN DAN SARAN}

Kinerja simpang Depok Kota Depok dalam kondisi yang kritis dan diperlukan penanganan dengan tundaan simpang yaitu 99,56 detik/smp dengan tingkat pelayanan $F$, sedangkan untuk derajat kejenuhannya mencapai angka kritis yaitu $>0,75$ dengan nilai pada masing - masing kaki simpang yaitu :

Kaki simpang utara $\quad: 0,99$

Kaki simpang selatan $: 0,99$

Kaki simpang barat $\quad: 0,99$

Kaki simpang timur $\quad: 0,99$

Berdasarkan hasil survei pada simpang Depok maka didapat tingkat keseriusan konflik pada waktu peak pagi yaitu 127 kendaraan terlibat konflik lalu lintas 81 kendaraan terlibat konflik serius dan 46 kendaraan terlibat konflik non serius.

Berdasarkan hasil analisisdirekomendasikan untuk pengaturanAPILL pada simpang Depok menggunakan pengaturan fasenya menjadi 3 fase yang membuat konflik lalu lintas berkurang. Rekomendasi menggunaan 3 fase yang telah dianalisis dapatmenurunkan jumlah terjadinya konflik, dimana pada kondisi eksisting terjadi 135 konflik dengan 88 konflik crossing dan 32 konflik merging dan setelah 
dilakukanperubahan jumlah konfliknya menurun menjadi 90 konflik dengan 58 konflik crossing dan 32 konflik merging.

\section{DAFTAR PUSTAKA}

. 2006. Peraturan Pemerintah No. 34 Tahun 2006 Tentang Jalan. Jakarta. . 2009. Undang-undang No. 22 Tahun 2009 Tentang Lalu Lintas dan Angkutan Jalan. Jakarta.

2017. Peraturan Pemerintah No. 37 Tahun 2017 Tentang Keselamatan Lalu Lintas dan Angkutan Jalan. Jakara.

Aan Komariah dan Djam'an Satori. 2010. Metodologi Penelitian Kualitatif Bandung : Alfabeta.

AASHTO. 2001. "A Policy On Geometric Design Of highway And Streets", New York. Adi, D K. (2001). Kamus Praktis Bahasa Indonesia. Surabaya : Fajar Mulya

Abubakar.dkk. 1995. Sistim Transportasi Kota, Jakarta, Direktur Jenderal Perhubungan Darat.

Ahmad Munawar.2004. Manajemen Lalu Lintas Perkotaan. Yogyakarta : Penerbit Beta Offset.

Alamsyah, A. Alik. 2005. Rekayasa Lalu Lintas. S. Amien (Ed). Malang : UMM.

C. Jotin Khisty \& B. Kent Lall. 2003. Dasar-dasar Rekayasa Transportasi jilid 1 edisi ketiga. Erlangga. Jakarta.

C. Jotin Khisty \& B. Kent Lall. 2005. Dasar-dasar Rekayasa Transportasi. Jilid I Jakarta: Penerbit Erlangga.

Direktorat Jenderal Bina Marga. 1991. TataCaraPerencanaanPersimpangan Sederhana Jalan Perkotaan. Jakarta

Direktorat Jenderal Bina Marga. 1997. Manual Kapasitas Jalan Indonesia (MKJI). Bina Karya . Jakarta.

Direktorat Jenderal Bina Marga. 1997. Manual Kapasitas Jalan Indonesia. Jakarta

Hobbs. $\quad$ FD. 1995. "Perencanaan Teknik Lalu Lintas ". Gajah Mada University Press. Yogyakarta.

Hydén, C., The development of a method for traffic safety evaluation : The Swedish Traffic Conflicts Technique. Bulletin 70., Institute för Trafikteknik, LTH, Lund, Sweden, 1987.

Iswahyudi. 2007. Evaluasi Kinerja Simpang Bundaran Baron Surakarta. Surakarta

Kementrian Pekerjaan Umum. 2015. "Panduan Kapasitas Jalan Indonesia". Dirjend Bina Marga. Jakarta.

Lawalata, Greece Maria, 2006. Pengaruh Pengaturan Petugas Tidak Resmi Pada Konflik diSatu Simpang-T, Tesis Program Pascasarjana Sistem dan Teknik Jalan Raya, Institut Teknologi Bandung, Bandung: Institut Teknologi Bandung.

Liliani, T. 2002. Catatan Kuliah Rekayasa Lalu Lintas. Bandung : ITB.

Milanisti, Kusuma. 2010. Analisa Simpang Bersinyal dan Tidak Bersinyal. Universitas Negeri Malang. Malang.

Moeheriono. 2012. "PengukuranKinerja Berbasis Kompetensi". Jakarta: Raja Grafindo Persada.

Morlok, E. K. 1988. Introduction toTransport Engineering and Planning didalam Pengantar Teknik dan Perencanaan Transportasi.

Johan K. Hainim (Penerjemah) cetakan Tahun1985. Jakarta : Erlangga. 
Morlok, E.K. 1998. Pengantar Teknikdan Perencanaan Transportasi (terjemahan John K Naimin). Jakarta : Erlangga

Nugraha, Gemilang Widya. 2016.Analisis Keselamatan Simpang Bersinyal Pada Simpang 4 Jetis Kota Salatiga. Tegal: Politeknik Keselamatan Trasnsportasi Jalan.

Poerwadarminta W.J.S. 1976. Kamus Umum Bahasa Indonesia, PN Balai Pustaka, Jakarta.

PTV VISION, 2015, PTV VISSIM 8User Manual. PTV AG, Karlsruhe, Germany.

Rizqi, Ahmad Shodiqur.2017. Evaluasi Pengaturan Simpang Tidak Bersinyal. Tegal: Politeknik Keselamatan Transportasi Jalan.

Soejachmoen, Kuki. H.2004. Keselamatan Pejalan Kaki dan Transportasi. Artikel Sugiyono. 2012. MetodePenelitianKuantitatif, Kualitatif dan R\&D. Bandung: Alfabeta Sugiyono. 2015. MetodePenelitianKuantitatif, Kualitatif, dan R\&D. Bandung: Alfabeta. Wikrama, Jaya.(2011). Analisis Kinerja Simpang Bersinyal. Jurnal Ilmiah Teknik Sipil. Denpasar. 